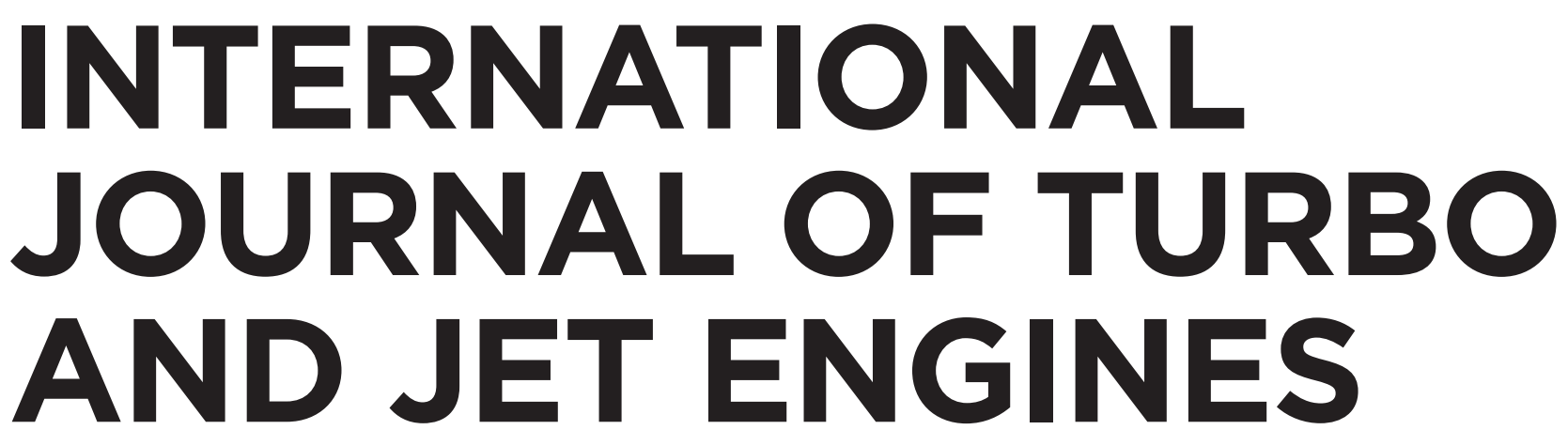

\title{
EDITOR-IN-CHIEF
}

Valery Sherbaum, Haifa

\section{EDITORIAL BOARD MEMBERS}

Ernesto Benini, Padova

Saeed Farokhi, Lawrence, KS

Rama S. R. Gorla, Cleveland, $\mathrm{OH}$

Changduk Kong, Kwangju

Yeshayahou Levy, Haifa

Debi Prasad Mishra, Kanpur

R. K. Mishra, Bangalore

Rishi S. Raj, New York, NY

Arvind Rao, Delft

Matsuo Shigeru, Saga

Yuan Wei, Chengdu

Shun-Peng Zhu, Shanghai

\section{DE GRUYTER}


ABSTRACTED/INDEXED IN Astrophysics Data System (ADS) · Baidu Scholar · CNKI Scholar (China National Knowledge Infrastructure) · CNPIEC: cnpLINKer · Dimensions · EBSCO (relevant databases) · EBSCO Discovery Service · Ei Compendex · Engineering Village · Gale/Cengage · Genamics JournalSeek · Google Scholar · Inspec · Japan Science and Technology Agency (JST) · J-Gate · Journal Citation Reports/Science Edition · JournalGuide $\cdot$ JournalTOCs $\cdot$ KESLI-NDSL (Korean National Discovery for Science Leaders) $\cdot$ Microsoft Academic $\cdot$ MyScienceWork $\cdot$ Naver Academic · Naviga (Softweco) · Primo Central (ExLibris) · ProQuest (relevant databases) · Publons · QOAM (Quality Open Access Market) · ReadCube · Reaxys · SCImago (SJR) · SCOPUS · Semantic Scholar · Sherpa/RoMEO · Summon (ProQuest) · TDNet · TEMA Technik und Management · Ulrich's Periodicals Directory/ulrichsweb · WanFang Data · Web of Science: Science Citation Index Expanded · WorldCat (OCLC)

The publisher, together with the authors and editors, has taken great pains to ensure that all information presented in this work (programs, applications, amounts, dosages, etc.) reflects the standard of knowledge at the time of publication. Despite careful manuscript preparation and proof correction, errors can nevertheless occur. Authors, editors and publisher disclaim all responsibility for any errors or omissions or liability for the results obtained from use of the information, or parts thereof, contained in this work.

The citation of registered names, trade names, trademarks, etc. in this work does not imply, even in the absence of a specific statement, that such names are exempt from laws and regulations protecting trademarks etc. and therefore free for general use.

All information regarding notes for contributors, subscriptions, Open access, back volumes and orders is available online at www.degruyter.com/tjj

ISSN 0334-0082 · e-ISSN 2191-0332

RESPONSIBLE EDITOR Valery Sherbaum, Haifa, e-mail: valerys@ technion.ac.il

PUBLISHER Walter de Gruyter GmbH, Berlin/Boston, Genthiner Straße 13, 10785 Berlin, Germany

JOURNAL COORDINATOR Torsten Krüger, De Gruyter, Genthiner Straße 13, 10785 Berlin, Germany, Tel.: +49 (0)30 260 05 - 176 , e-mail: torsten.krueger@degruyter.com

RESPONSIBLE FOR ADVERTISEMENTS Markus Kügel, De Gruyter, Rosenheimer Str. 143, 81671 München, Germany, Tel.: +49 89 76 902-424, e-mail: anzeigen@degruyter.com

(C) 2021 Walter de Gruyter GmbH, Berlin/Boston, Germany

TYPESETTING TNQ Technologies, Chennai, India

PRINTING Franz X. Stückle Druck und Verlag e.K., Ettenheim

Cover Illustration: Hemera/Thinkstock

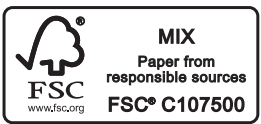




\section{Contents}

\section{Review}

S. K. Muduli, R. K. Mishra and P. C. Mishra

Assessment of Exit Temperature Pattern Factors in an Annular Gas Turbine Combustor: An Overview — 351

\section{Original Research Articles}

V.G. Krishna Anand and K.M. Parammasivam Optimization of Trenched Film Cooling Using RSM Coupled CFD -363

Tolga Baklacioglu, Onder Turan and Hakan Aydin Modeling of Relative Exergy Destruction for Turboprop Engine Components Using Deep Learning Artificial Neural Networks — 377

Qiangang Zheng, Ziyan Du, Dawei Fu, Zhongzhi Hu and Haibo Zhang

Direct Thrust Inverse Control of Aero-Engine Based on Deep Neural Network — 391

Hakan Aygun and Onder Turan

Entropy, Energy and Exergy for Measuring PW4000

Turbofan Sustainability 397

Antonios Fatsis, Nikolaos Vlachakis and George Leontis A Centrifugal Compressor Performance Map Empirical Prediction Method for Automotive Turbochargers — 411
Shaowen Chen, Qinghe Meng, Yueqi Liu, Hongyan Liu and Songtao Wang

Unsteady Numerical Simulation in a Supersonic Compressor Cascade with a Strong Shock Wave _- 421

Arun Kumar Pujari

CFD Study of Combined Impingement and Film Cooling Flow on the Internal Surface Temperature Distribution of a Vane -433

Rakesh Kumaraswamy, Karthikeyan Natarajan and R. B. Anand

CFD Analysis of Flow and Performance Characteristics of a $90^{\circ}$ curved Rectangular Diffuser: Effects of Aspect Ratio and Reynolds Number — 451

Lei Sun, Yong Huang, Ruixiang Wang, Xiang Feng and Zhilin Liu

Effects of the Recess Length of the Pilot Stage on the Lean Blowout Limits for the Multipoint Lean Direct Injection Combustors -465

Daniel-Eugeniu Crunteanu, Vlad-Alexandru Popa and Mihail Sima

Stress and Vibration Analysis of a PDC (Pulse Detonation Chamber) -479

Shan M. Assis, Jeyakumar Suppandipillai and Jayaraman Kandasamy

Transverse Injection Experiments within an Axisymmetric Scramjet Combustor -489 